WellBeing International

WBI Studies Repository

1992

\title{
Ethical Ideology, Animal Rights Activism, and Attitudes Toward the Treatment of Animals
}

\author{
Shelley L. Galvin \\ Western Carolina University \\ Harold A. Herzog \\ Western Carolina University
}

Follow this and additional works at: https://www.wellbeingintlstudiesrepository.org/acwp_sata

Part of the Animal Studies Commons, Civic and Community Engagement Commons, and the Politics and Social Change Commons

\section{Recommended Citation}

Galvin, S. L., \& Herzog Jr, H. A. (1992). Ethical ideology, animal rights activism, and attitudes toward the treatment of animals. Ethics \& Behavior, 2(3), 141-149.

This material is brought to you for free and open access by WellBeing International. It has been accepted for inclusion by an authorized administrator of the WBI Studies Repository. For more information, please contact wbisr-info@wellbeingintl.org.

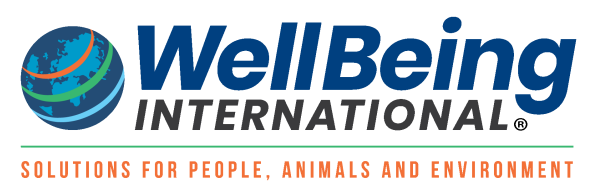




\title{
Ethical Ideology, Animal Rights Activism, and Attitudes Toward the Treatment of Animals
}

Shelley L. Galvin, Harold A. Herzog, Jr.

Western Carolina University

\begin{abstract}
In two studies, we used the Ethics Position Questionnaire (EPQ) to investigate the relationship between individual differences in moral philosophy, involvement in the animal rights movement, and attitudes toward the treatment of animals. In the first, 600 animal rights activists attending a national demonstration and 266 nonactivist college students were given the EPQ. Analysis of the returns from 157 activists and 198 students indicated that the activists were more likely than the students to hold an "absolutist" moral orientation (high idealism, low relativism). In the second study, 169 students were given the EPQ with a scale designed to measure attitudes toward the treatment of animals. Multiple regression showed that gender and the EPQ dimension of idealism were related to attitudes toward animal use.
\end{abstract}

\section{KEYWORDS}

animal rights, moral philosophy, ethical attitudes

The animal rights movement has had a major impact on public opinion concerning the use of nonhuman species. It is also becoming the focus of research by social scientists. There is an emerging demographic picture of the movement with virtually all studies finding that activists tend to be disproportionately female, White, well-educated, middle to upper middle class, politically liberal, and childless (Jamison \& Lunch, in press; Jasper \& Nelkin, 1992; Kaplan \& Herzog, 1991; Pious, 1991; Richards \& Krannich, in press).

Although animal activists are sometimes portrayed by their opponents as "crazies," there are few empirical studies of psychological aspects of involvement in the movement. Kimball and Broida (1991) reported that students who opposed animal experimentation tended to be intuitive feeling types based on the Myers-Briggs Type Indicator, a popular personality inventory. Herzog (in press) interviewed 27 rankand-file activists. Many seemed obsessed with their cause and were struggling with the demands of a heavy moral burden; none, however, showed signs of serious psychopathology. On the other hand, many of the activists interviewed were idealistic in their moral vision and were convinced of the correctness of their beliefs. This combination of idealism and ideological certainty gives the animal rights movement the aura of what has been termed a moral crusade (Jasper \& Nelkin, 1992). 
Forsyth (1980) argued that the two dimensions of idealism and moral relativism constitute the central components of a concept he calls ethical ideology-the assumptions that individuals make about how ethical conflicts should be resolved. Within this framework, relativism is the degree to which individuals accept the belief that moral decisions should be based on universal principles. Idealism refers to the extent to which individuals believe that ethical behavior will always lead to positive consequences. In the research reported here, we examined the relationship between these concepts and animal activism.

To measure individual differences in these dimensions of personal moral philosophy, Forsyth (1980) developed a standardized instrument, the Ethics Position Questionnaire (EPQ). The EPQ consists of 20 nine-point Likert scale statements, half measuring relativism and half measuring idealism. Individuals are typically classified as having one of four possible ethics positions based on splits along the two dimensions (Forsyth \& Pope, 1984). The EPQ has acceptable psychometric properties and is related to a variety of attitudes toward moral and social issues (Forsyth, 1980; Forsyth, Nye, \& Kelley, 1987).

Situationists (high relativism, high idealism) believe there are no universal moral principles to guide behavior and that well-being is maximized and interests are protected through cost-benefit analyses of individual acts. Absolutists (low relativism, high idealism) hold that there are universal moral principles and that adherence to them will lead to positive consequences and the protection of the general welfare. Subjectivists (high relativism, low idealism) do not believe that morality should follow universal principles or that doing the right thing will always produce positive outcomes; they view personal values as an appropriate basis for moral judgment. Exceptionists (low relativism, low idealism) subscribe to universal moral principles, yet they are pessimistic about the prospect that good results will inevitably result from moral behavior. As a result, they are pragmatically open to exceptions to universal principles.

In the first part of the present study, we used the EPQ to examine the ethical ideologies of animal rights activists by administering the EPQ to participants attending a large national animal rights demonstration. We hypothesized that they would fall disproportionately into the absolutist category. We also investigated whether the EPQ items would be interpreted similarly by activists and nonactivists. In the second part, we used multiple regression to examine the relationship between the dimensions of ethical ideology, gender, and attitudes toward the use of animals in a nonactivist sample.

\section{STUDY 1}

Method

Six hundred questionnaires were distributed to demonstrators at the March for the Animals in Washington, DC, held June 10, 1990. The march was the first large-scale national animal rights demonstration, attracting approximately 25,000 participants. We approached individuals at the large premarch rally on the White House Ellipse on an ad hoc basis. We informed them that we were interested in the attitudes of animal rights activists and asked if they would fill out the questionnaires at their leisure and return them by mail. The research packet contained the EPQ, a demographic questionnaire, an attitude survey, and a preaddressed postage paid envelope. Although we did not obtain data on the number of refusals, we estimate that less than $10 \%$ of persons approached declined to take the research packet.

The EPQ was originally tested and validated with college students, and we felt that some of the statements on the Idealism subscale might be interpreted differently by activists and nonactivists. For example, one item states, "The dignity and welfare of people should be the most important concern in society." Presumably, this statement would be answered affirmatively by idealistic individuals. Idealistic animal rights activists, however, might circle "strongly disagree." They might deem that the framing of the 
statement in terms of the well-being of people, rather than all sentient creatures, reflects what animal rights philosophers term speciesism (e.g., Regan, 1983; Singer, 1975). For this reason, we suspected that the Idealism subscale of the EPQ might underestimate this dimension in this group. To reduce this problem, on 400 of the EPQs, we substituted the term being on the items that incorporated the term person (Items 1 through 6, 8 and 9). A line in the instructions of the modified EPQs was added noting that the term being referred to both human and nonhuman animals. Two hundred of the demonstrators were given packets containing the original form of the EPQ.

For comparative purposes, 266 college students enrolled in introductory psychology courses at Western Carolina University were also given the EPQ; half of the students were given the original form and half the modified form. The questionnaires were distributed to volunteers in class, and the students were asked to complete them at their convenience and return them to a box located in the Psychology Department.

\section{Results}

One hundred three research packets containing the modified form of the EPQ and 54 with the original form were returned by the activists, a return rate of $26 \%$. The students returned 101 original and 97 modified forms of the EPQ, a return rate of $74 \%$. Questionnaires were returned from activists in 31 states. The majority of activists returning the packet were women (121 women vs. 36 men), which is consistent with other studies of activists (Jamison \& Lunch, in press; Pious, 1991; Richards \& Krannich, in press).

TABLE 1. Percentage of Animal Rights Activists and College Students in Moral Orientation Categories as Determined by the Ethics Position Questionnaire (EPQ)

\begin{tabular}{|lcccc|}
\hline & \multicolumn{2}{c}{ Modified EPQ } & \multicolumn{2}{c|}{ Original EPQ } \\
\cline { 2 - 5 } EPQ Category & Activists $^{a}$ & Students $^{b}$ & Activists $^{c}$ & Students $^{d}$ \\
\hline Situationists & 18 & 30 & 21 & 23 \\
Absolutists & 76 & 25 & 57 & 38 \\
Subjectivists & 0 & 18 & 2 & 15 \\
Exceptionists & 7 & 29 & 19 & 25 \\
\hline
\end{tabular}

${ }^{a} n=103,{ }^{b} n=97,{ }^{c} n=54,{ }^{d} n=101$.

As expected, activists returning the modified EPQ had higher idealism scores $(M=7.83)$ than those returning the original form $(M=7.15)$, a difference that was statistically significant, $t(154)=3.16, p=.002$. There was no difference in the relativism scores of the two groups, and the idealism and relativism scores did not differ between college students who were given the two forms. Thus, the wording on the Idealism subscale of the EPQ was interpreted differently by activists and nonactivists.

Following D. R. Forsyth (personal communication, September 1990), a cutoff score of 6.1 on the Idealism and Relativism subscales was used to assign subjects to the four EPQ categories. The percentages of the activists and college students in the categories are shown in Table I. A larger proportion of activists than students were classified as absolutists, and a smaller proportion of activists were classified as subjectivists. There was a statistically significant difference in the distributions of the two groups using both the modified, $\chi^{2}(3, N=200)=59.801, p<.001$, and the original, $\chi^{2}(3, N=154)=8.989, p<.05$, 
versions of the EPQ. The idealism and relativism scores of our student sample did not differ from means of responses of the subjects used by Forsyth (1980) to validate the scale.

\section{Discussion}

The majority of activists who returned the survey held attitudes reflecting the absolutist approach to moral decision making. It might be expected that moral absolutism would be associated with fundamentalist religious beliefs. The demographic information we obtained for the respondents indicated, however, that the majority were not affiliated with traditional denominations. Forty- eight percent reported that they were atheists or agnostics, 15\% held pantheistic religious beliefs (e.g., "God is in nature"), and 4\% were Buddhists. Only 34\% claimed membership in mainstream denominations (Protestant, Catholic, Jewish), but the fact that most activists are not affiliated with conventional religious groups does not mean that there is not a religious component to the involvement of many activists. Indeed, there are significant parallels between conversion to fundamentalist religion and animal rights perspectives (Herzog, in press; Jasper \& Nelkin, 1992; Sperling, 1988).

There are several provisos that should be kept in mind when interpreting these results. First, any classification system in which complex individuals are placed into simple categories is limited. Animal rights activists hold a diversity of views (Herzog, in press; Jasper \& Nelkin, 1992; Pious, 1991), and it would be inaccurate to paint all activists with the same brush on the basis of a survey. Second, our results should be viewed in light of the return rate and possible sampling bias. The possibility that the absolutists were more likely to return the questionnaires than other groups cannot be dismissed.

We believe, however, that these findings are reasonably valid for several reasons. There were other research teams at the March for the Animals using on-the-spot interviews rather than mail-in questionnaires. These teams reported high response rates and obtained approximately random samples (Jamison \& Lunch, in press; Pious, 1991). The demographic information obtained from our respondents, although not the subject of this article, was essentially identical to that obtained by these research groups. This leads us to believe that our results typify the march participants. In addition, the conclusion that activists tend to be idealistic and nonrelativistic in their moral thinking is supported by evidence from qualitative studies of animal activists (Herzog, in press; Jasper \& Nelkin, 1992; Sperling, 1988).

We felt, however, that the case for a connection between ethical ideology and animal rights activism would be strengthened if a relationship between the EPQ scales and attitudes toward the use of animals could be shown among nonactivists. The second study examined this relationship.

\section{STUDY 2}

The purpose of the second study was to examine the relationship between the ethical idealism and relativism and attitudes toward the animals in a group of individuals who were not involved in the animal rights movement. Gender is known to be a major factor influencing these attitudes (Gallup \& Beckstead, 1988; Herzog, Betchart, \& Pittman, 1991; Kellert \& Berry, 1987), and we were interested in determining the relative independent contributions of the EPQ dimensions and gender to individual differences in attitudes toward the ethics of treatment of other species.

\section{Method}

The subjects were 112 women and 57 men enrolled in social psychology and experimental psychology courses at the University of Tennessee. The average age of the participants was 22 years. The students were given extra credit in return for their participation. 
The students were given the EPQ and a 20-item Likert scale designed to assess attitudes about the morality of common uses of animals in American society. The scale was a slightly modified version of the Animal Attitude Scale used by Herzog et al. (1991). Typical items included, "It is morally wrong to hunt wild animals just for sport," "Much of the scientific research done with animals is unnecessary and cruel," and "Too much fuss is made over the welfare of animals these days when there are many human problems to be solved." High scores on the scale reflect greater concern for the welfare of other species.

\section{Results}

There was a significant correlation between the EPQ idealism scores and scores on the attitude scale $(r=$ $.313, p<.01)$. The correlation between the relativism and the attitude scale scores was not statistically significant $(r=-.014)$. The Idealism and Relativism subscales of the EPQ were uncorrelated $(r=.067)$, a finding also reported by Forsyth et al. (1987). Multiple regression was applied to the data using gender and the two EPQ subscales as independent variables and the animal attitude scale score as the dependent variable. The resulting multiple $r=.429$ (adjusted $r^{2}=.174, \mathrm{~F}(2,167)=18.76$ ). Gender and idealism, but not relativism, proved to be significant predictor variables (standardized regression weights: gender $=.301$, idealism $=.248$ )

\section{Discussion}

The results indicate that gender and ethical ideology (particularly idealism) independently contribute to attitudes about the treatment of animals. We have already alluded to the predominance of women in the animal rights movement. Gilligan (1982), in a well-known and controversial book, argued that women are more inclined than men to base moral judgments on caring rather than justice. Shapiro (1992) analyzed autobiographical accounts of leaders of the animal protection movement and found that caring was a central trait theme in their moral development. It is possible that ethical idealism is related to empathy, which would lead to increased concern for other creatures. Direct support for this hypothesis is not available. However, Forsyth et al. (1987) investigated the relationship between Gilligan's model and the EPQ dimensions of relativism and idealism. They found that idealism $(r=.53)$ was more related to a scale designed to measure the ethic of caring than was relativism $(r=-.13)$ and that absolutists had the highest caring orientation scores.

\section{GENERAL DISCUSSION}

Our results indicate that differences in personal moral philosophy are related to how individuals feel animals should be treated. In the first study, the majority of a sample of activists attending a national animal rights demonstration were shown to hold an absolutist ethical ideology, an orientation characterized by the belief that moral principles are universally applicable and by the view that the best results come from adhering to these principles. In the second study, we found that the idealism dimension of ethical ideology coupled with gender predicted a significant amount of variation in attitudes toward the treatment of animals in a sample of college students.

Our findings raise several interesting questions. First, is there a causal relationship between ethical ideology and involvement in social issues? The argument is sometimes made that there is little, if any, relationship between moral philosophy and behavior (e.g., Burghardt \& Herzog, 1980; Forsyth, 1980; Forsyth \& Berger, 1982). The finding that animal activists are highly represented in some EPQ categories and not in others suggests that this may not be the case. We were particularly struck by the near absence of subjectivists among the demonstrators. Second, is it possible that some moral orientations essentially inoculate the holder against becoming involved in social movements? EPQ data from a larger sample of 
animal rights activists and information on the ethical ideologies of members of similar social movements (e.g., anti- and proabortion activists) would help clarify this issue.

Our results have methodological implications. A minor change in the wording ofEPQ Idealism subscale items (i.e., substituting the term being for people) resulted in significantly higher idealism scores among animal rights activists but not students. Thus, the standard version of the EPQ underestimates idealism in this population. Social scientists need to exercise caution when comparing attitudes of members of different groups based on surveys such as the EPQ. In this case, animal activists interpreted the same questions differently from nonactivists.

The finding that ethical ideology is related to attitudes about the use of animals has ramifications for the public debate over the use of animals in research. Absolutists have been reported to be more likely than those in the other EPQ categories to take extreme stands on social issues, and they are harsher in making judgments about the behavior of others and their own moral failings (Forsyth, 1980; Forsyth \& Berger, 1982). They may be less willing to compromise their positions than individuals who view moral judgment through a more relativistic lens. Although data are not available on the ethical orientation of animal researchers, it would not be surprising to find that they are less likely than activists to hold the moral world view that Forsyth refers to as absolutist. Research comparing the underlying assumptions of researchers and activists is needed. In light of our results, it is not surprising that scientists and activists have difficulty reaching common grounds for discussion.

\section{ACKNOWLEDGMENT}

We thank Robbie Pittman, Robin Kowalski, and Mary Jean Herzog for their comments on the article and Monica Schneider and Roberta Dewick for their help with data collection and analysis.

\section{REFERENCES}

Burghardt, G. M., \& Herzog, H. A., Jr. (1980). Beyond conspecifics: Is Brer Rabbit our brother? BioScience, 30, 763-768.

Forsyth, D. R. (1980). A taxonomy of ethical ideologies. Journal of Personality and Social Psychology, 39, 175-184.

Forsyth, D. R., \& Berger, R. E. (1982). The effects of ethical ideology on moral behavior. Journal of Social Psychology, 117, 53-56.

Forsyth, D. R., Nye, J. L., \& Kelley, K. (1987). Idealism, relativism and the ethic of caring. Journal of Psychology, 122. 243-248.

Forsyth, D. R., \& Pope, W. R. (1984). Ethical ideology and judgement of psychological research: Multidimensional analysis. Journal of Personality and Social Psychology, 46, 1365-1375.

Gallup, G. G., \& Beckstead, J. W. (1988). Attitudes toward animal research. American Psychologist, 43, 474-476.

Gilligan, C. (1982). In a different voice. Cambridge, MA: Harvard University Press.

Herzog, H. A., Jr. (in press). "The movement is my life": The psychology of animal rights activism. Journal of Social Issues. 
Herzog, H. A., Jr., Betchart, N. S., \& Pittman, R. (1991). Gender, sex roles, and attitudes toward animals. Anthrozoos, 4, 184-191.

Jamison, W., \& Lunch, W. (in press). The rights of animals, science policy and political activism. Science, Technology and Human Values.

Jasper, J.M., \& Nelkin, D. (1992). The animal rights crusade: The growth of a moral protest. New York: Free Press.

Kaplan, S. G., \& Herzog, H. A., Jr. (1991, April). The ethical ideology of animal rights activism. Paper presented at the meeting of the Southeastern Psychological Association, New Orleans.

Kellert, S. R., \& Berry, J. K. (1987). Attitudes, knowledge, and behaviors towards wildlife as affected by gender. Wildlife Society Bulletin, 15, 363-371.

Kimball, R., \& Broida, J.P. (1991). Psychological profiles of students for and against vivisection using the Myers-Briggs Type Indicator. Humane Innovations and Alternatives, 5, 232-235.

Pious, S. (1991). An attitude survey of animal rights activists. Psychological Science, 2, 194-196.

Regan, T. (1983). The case for animal rights. Berkeley: University of California.

Richards, R. T., \& Krannich, R. S. (in press). The ideology of the animal rights movement and activists' attitudes towards wildlife. Transactions of the North American Wildlife and Natural Resources Conference.

Shapiro, K. (1992, March). On being an animal rights activist. In H. Herzog (Chair), Understanding animal rights activism. Symposium conducted at the meeting of the Southeastern Psychological Association, Knoxville.

Singer, P. (1975). Anima/liberation. New York: New York Review.

Sperling, S. (1988). Anima/liberators: Research and morality. Berkeley: University of California. 